\title{
Can Emergency Medicine become Redundant?
}

\section{Hague $A^{*}$}

CellSonic: Manufacturers of Medical Equipment, United Kingdom

*Corresponding author: Andrew Hague, President, CellSonic: Manufacturers of Medical

Equipment, United Kingdom, Tel: +1 315210 6307; Email: cellsonic.beauty@gmail.com

\section{Clinical Note}

Volume 3 Issue 3

Received Date: May 12, 2019

Published Date: June 04, 2019

DOI: $10.23880 /$ eoij-16000209

\section{Abstract}

So long as there are emergencies, we shall need emergency doctors. Is it unrealistic to believe that we can plan our lives so that emergencies never happen? Utopia is dreamland, it is said, but nevertheless, without such visions we have no sense of direction. If the unexpected can be anticipated and avoided then pain, suffering and disruption is minimised.

\section{Injury and Illness}

Injury and illness are the two medical problems. Injury can be sudden and requires emergency treatment. Illness is incremental and treated progressively.

\section{Doctors are Role Models}

Much work is done to prevent illness. We see this in better hygiene, personal and social; washing hands and sanitation. Lifestyle affects health and people are advised on diet and exercise. The equivalent advice from doctors about emergencies and injuries is missing. In all societies, doctors are role models. We all grew up thankful for the attention of a doctor at some stage. They brought us into this life and will see us out. Seldom do they pronounce on politics and although they have a good income are never seen as having more than their fair share of wealth. People respect doctors and this status should be used by doctors to influence behaviour. Doctors, whether they like it or not, are role models. What they say, is influential.

\section{Causes of Injury}

There are four classes of causes of injury:

1. Carelessness

2. Recklessness

3. Aggression

4. Misfortune
From the first of carelessness to the last of misfortune, the chance of avoiding disaster gets less which means that a doctor has less influence. Nevertheless, statements by doctors will be heeded and when it is understood that the doctor invites redundancy this advice will be respected. We wish for the same from the police and fire brigades. Indeed, the fire service devotes a lot of effort to inspecting buildings for fire safety. Do the police invest time preventing crime or is that left to the deterrent effect of sentencing and punishment? In many cases, it is hoped that people will be careful to avoid injury but still they turn up at the A\&E in pain and talking about accidents. Investigators admit that the truth is there are no accidents, only mistakes that were avoidable.

\section{Consequences}

A child has no concept of consequences. Over time, by trial and error coupled to imitation, the process of conditioning adds to the memory bank and the child becomes an adult aware of the consequences of their actions. People who have not acquired this knowledge should be recognized by doctors for their ignorance which will become evident in frequent visits to the clinic. Their teachers will have already identified these people at school as slow learners. It is in these encounters that doctors have a role to play.

Interestingly, the accident prone are not always those scoring low in education. There are many explanations for mistakes. The person who does nothing may stay safe but 


\section{Ergonomics International Journal}

achieve nothing and the ambitious may push the boundaries of sense to explore beyond. This is the consequence of having the brain we acquired when we mutated into homo sapiens.

\section{Carelessness}

There is an assumption that tidiness is safer than a mess. Do more accidents happen in a messy or tidy workplace? I do not know but from my own experience and this includes owning a factory for many years, a mess is not the cause of mistakes and tripping over wires. Where there are obvious dangers, people are alert and avoid them. When there is deceptive safety, one's attention can wander letting the day dreamer trip or walk into a half open door.

Our brains are not born to cope with neatness. The cave and the jungle floor are always a tangle and walking depends on watching where to put your feet for every step. Only since manufacturing required orderliness has a clear path become essential. This allows carelessness.

There is the often-quoted story of two mountaineers trying to find their way to the Royal Geographical Society through the back streets of London. These men had climbed the world's mountains and then one of them tripped over the kerb when crossing the road in London and broke his leg. As a doctor, what can you advise to prevent such mishaps? Obviously, the fellow was safer on Mount Everest than the paved streets of London.

I visit many countries and complain when I cannot drink the tap water and walk at ease in the towns because of the holes in the pavements. However, I do admit that the locals never seem to fall on those pavements and neither did I; I had to watch where I was going.

Carelessness is thus a response to a deceptively safe situation. Add some dangers, as our cavemen-forebears expected, and there should be fewer accidents.

Modern manufacturing which is as automated as possible has reduced the chances of injury. Earlier methods often allowed the operator to injure themselves. Working a fly press involves placing the component under the press tool and swinging the handle to bring the tool down with a load of anything from 5 to 50 tons. Repeating this cycle ten times a minute creates a rhythm of complacency. When the left hand moves before the right hand instead of the other way around, the hand can be under the press with disastrous consequences. Later improvements were to install guards; the guard came down before the press. That resulted in some cases of the guard trapping the hand preventing it being withdrawn from danger. The operator had to wait a second, which can be a long time in these circumstances, for their hand to be amputated in one blow. Eventually, designers arranged for the descent of the press to be controlled by two buttons, one a shoulder's width away from the other so that both hands had to be on a button before and whilst the press came down. The release of one button would stop the descent of the press and interrupt the cycle. Automatic pick and place machines have mostly replaced human press loading and it is only where labour costs are so low that investment in automation cannot be justified that workers are exposed to dangers. Automation is criticised for creating unemployment. It actually increases productivity and safety. Only the setter, the person setting the tools under the press, is in danger when preparing a new tool in the production process. As the setting task is not repetitive with each step having to be thought about, the injuries are fewer.

Setters were in danger if someone switched on the machine not realising there was a person at the back or inside. These calamities not only resulted in death but led to claims of manslaughter incriminating the person who switched on the machine and the employer. The answer was for the setter to isolate the machine and withdraw a key to the control box, lock it and keep the key in his pocket so that the machine remained inactive until the setter switched on again.

\section{Recklessness}

This is where we remember the story of the boy cycling around the house and as he takes his hands off the handlebars he shouts, "Look Mummy, no hands". A few minutes later he reappears and shouts, "Look Mummy, no teeth". Due to his bravado, he had crashed. The same happens driving cars at speed, playing with knives or generally showing off.

The need to be reckless, seen more in youth than maturity, is shuffling into pecking order to find a place in the hierarchy of society. Less skill means more crashes and you slip down the scale of ability. Balance a football on your nose and the crowd will cheer. Humans play these games because they position each person where they can best support the tribe.

Modern society does not depend on physical skills. The computer nerd is today's leader. When a doctor explains to the children at the local school that fooling about is dangerous, some sense may prevail and lead to fewer injuries. Recklessness will persist because the desire to show physical prowess is innate. 


\section{Ergonomics International Journal}

With education essential for survival today, the clever ones are revered and this will have an effect on our species as physical strength and agility is less desirable in the gene pool compared to mental ability. All species adapt to the environment or become extinct. The human environment is changed by our own behaviour and we are these days in the midst of an evolutionary shift. The damage we inflict on the environment causing climate change is expected to lead to our extinction. It certainly will but only if it kills us before we kill ourselves by preventing deaths through extended longevity so that adaptive mutations cease. This is a medical emergency beyond the ability of emergency doctors.

\section{Aggression}

Lack of fear and aggression goes together. When a wild dog approaches a group, it will sense the meek one who is afraid and attack. This is enabled by the electrical circuits and magnetic fields by which brains operate and is how humans and animals can relate to each other. As a doctor, you will have learned little about this at medical school and yet it is fundamental to behavioural studies and cancer [1]. Aggression is useful in primitive society when dealing with predators, less so in a civilised society. The military employs soldiers trained as commandos, to operate behind enemy lines and, where necessary, kill with their bare hands. Such a person, who can emerge from an assignment and look unperturbed, is almost unknown. When the fictional James Bond peals off his diving suit and walks nonchalantly into the bar for a drink shaken and not stirred, he is nothing more than entertainment. The brain does not work that way. An actor can play the role to the cameras but in real life, the adrenalin and tension involved dominates the soldier and, for many of these people, rehabilitation is difficult.

As a doctor, dealing with the effects of aggression, especially when coupled with alcohol and drugs, is a nightmare. To stop it would amount to eliminating those people programmed to be aggressive. Either they find a role in the security forces or we hope they obey the law or they become useful to organised crime. The doctor will sense these attributes in a young person. I doubt they can be ameliorated. The only way is to direct that person into a role where they can be useful and the military is an opportunity.

\section{Misfortune}

This is being in the wrong place at the wrong time. There is little a doctor can do to prevent victims being struck by misfortune. Awareness of danger is everywhere. Entertainment media dwells on buildings exploding, cars flying off the road and rolling down the mountain, jumping put of a plane and landing safely in a haystack. I feel that this awareness diminishes the sense of danger rather than creating risk avoidance.

News programmes refer to natural disasters. They are not disasters. Avalanches, earthquakes, floods and forest fires are natural phenomena that have occurred since the earth was formed and will continue after our species is extinct. In many cases, they are predictable and thereby avoidable. Modern weather forecasting can give two days' notice of a cyclone or hurricane, time enough to move people to shelter. Living on the side of a volcano where the soil is fertile is always tempting but the gases rolling down from the crater can be poisonous and when the volcano erupts the lava is destructive. You don't need to be a doctor or a geologist to warn of such dangers.

This is where the sober, thoughtful advice of a doctor carries a lot of weight. Every community has its danger areas. It may be the high cliffs, a motorway, a mosquito ridden swamp, places where the unsuspecting can get into trouble. Tell the community leaders. They will listen to you. Fences can be erected at the edges of the cliffs and busy road and the swamp can be sprayed to control the mosquitos. Always present a solution to the problem and be sure you have no relationship with the contractor who will carry out the work.

\section{Psychology}

Preventing injuries involves more psychology than physical medicine. Psychology still falls within the skills of a doctor. There is little scope for direct action. The best a doctor can do is influence and advise and it is by being a doctor that notice will be taken of your advice. The inevitable conclusion will be that humans are accident prone and seek rather than avoid trouble. The doctor is then expected to repair the injuries just as a garage would fix a car damaged in a crash.

The Government of Western Australia Department of Health reports that the most common injuries are [2]:

- road crashes (external site)

- suicide and self-harm (external site)

- falls (external site)

- drowning (external site)

- poisoning (external site)

- violence (external site)

- burns and scalds (external site)

I have left their hyperlinks in place. The extent that the injuries can be traced back to psychological causes differs. 


\section{Ergonomics International Journal}

Certainly, a disturbed mind leads to suicide and violence and very likely to road crashes.

Many years ago, when I was teaching sociology to an adult college class in which we were studying criminology, I proposed a cure that I still believe is the only cure and is in most cases impossible; the cure for criminality is to sentence the criminal to a good home. Here is a murderer. Please love him.

The explanations were made by John Bowlby in the 1960s and earlier. His best-read book is Child Care and the Growth of Love [3]. Only by parental love can a child acquire empathy and be able to pass love on to others. These bonds are essential in human groups and exist in all animals. Recent botanical research adds to this insight by finding electrical relationships between plants. A person who grew up unloved can be expected to not fit into society. They will not accept the common rules of behaviour and be unaware of others' feelings. Without empathy, cruelty is easy. Should this individual become a parent, the children will also lack bonds.

Doctors will recognise these people and their disruptive, often temporary, families. They are crimes and injuries in the making. What can a doctor do to prevent future mishaps? On the face of it, very little. Most doctors work inside a bureaucracy and there will be no scope for interfering in a patient's private life, for that it is how it will be perceived. In earlier times, religious leaders would step in but their leadership has given way to the smart phone screen which can not love, only excite and provoke. Sociologists call it alienation and anomie; being cut off from society and having no feeling of belonging. If this were the lack of vitamins or a virus infecting the blood, a doctor could and would do something. The affected (instead of infected) patient is equally in need of help but seldom is a doctor seen as the person to turn to. Eventually, it will be the police and their aim is to pass to the courts, then prison. Society offers no cure despite knowing the cause and suffering the consequences. If what cures is medicine, then here we need social medicine. I contend that doctors apply medicine. If it is not the police to become involved, at least it will be the emergency doctor stitching up knife wounds.

Even amongst well brought up people there is a range of temperaments from placid to impetuous. Impatience can cause injury. Think of bad driving or pushing in a queue. Does such an irritable person need a tranquiliser? Theoretically, extreme behaviours could be chemically restricted, a technique sure to cause ethical arguments.

People self-administer their personality shift with alcohol in one direction and caffeine in the other. I advise against both drugs but they are popular. Medically there is no safe upper limit for alcohol. Coffee is fully accepted, approved and big business. Politicians create laws, companies lobby politicians and consumers accept laws. I love coffee, its taste and smell, but I read my own senses and something tells me to be wary; minimise on coffee. Look after the brain for a healthy body. Anything that affects the brain is dangerous. This does not include listening to Beethoven.

I have little sympathy with addiction because I see it as self-inflicted. More compassionate souls feel sorry for those who cannot stop doing something. In the context of injuries, think of speed and racing. The winner is the one who placed their life most a risk. That is stupid but the audience loves it and next time greater risks will be taken. Confined to a race track, only the participants get hurt. On the open road, you and I can be hit. I remember a doctor assigned to a Formula One racing team explaining that every bone in their star driver had been broken at least once. Didn't that put him off? No, he is addicted and nothing will stop him. At the end of the line, the publicity was increasing the sales of something.

\section{Trauma Infection}

The first action on a trauma patient brought into Accident and Emergency on a stretcher, assuming the bleeding has been staunched by the medics, is to treat with a CellSonic VIPP machine to kill all and any infection. The intense pulses will penetrate to catch germs thrust into the wound. Importantly, stem cells of the right type in the right quantity will be delivered in the blood to exactly the right place by the immune system responding to the pulses. The blood will automatically have more oxygen and growth factors to aid healing. All this can be done before the doctor arrives to inspect the patient. Professor Richard Coombes, an orthopaedic surgeon of Charing Cross Hospital in London always said that CellSonic VIPP machines should be standard equipment in all emergency units. After the wounds and bones have been set, use the CellSonic again to kill any infection. This can be instead of antibiotics or allow a much lower dose of antibiotic. The benefit is saving the patient from developing antibacterial resistance and reducing the contamination of local rivers whereby antibiotics travel through the patient and the sewage system to rivers where fish and surrounding land are contaminated. 


\section{Ergonomics International Journal}

\section{Conclusion}

Doctors can help to reduce the demand for emergency medicine. It requires an extension of their usual skills into the therapy of psychology and social manipulation. Humans have brains which search for change. In the process, they hurt themselves and each other and call upon doctors in an emergency. If a more placid life is desirable, emergencies will be rare but that is not the current trend. Expect more horrors.

\section{References}

1. Andrew H (2019) Cancer and Wounds are Similar@. Nov Appro in Can Study 2(4): NACS.000543.

2. What causes injury?

3. John B (1953) Child Care and the Growth of Love. Penguin Books, Harmondsworth. 